\title{
Parameter Monitoring and Control in industrial sewing machines - An integrated approach
}

\author{
Helder Carvalho \\ University of Minho \\ Dep.Textile Engineering \\ Campus de Azurém \\ 4800-058 Guimarães, \\ Portugal \\ helder@det.uminho.pt
}

\author{
Ana Rocha \\ University of Minho \\ Dep.Textile Engineering \\ Campus de Azurém \\ 4800-058 Guimarães, \\ Portugal
}

amrocha@det.uminho.pt
João L. Monteiro

University of Minho

Dep.Ind. Electronics

Campus de Azurém

4800-058 Guimarães,

Portugal

monteiro@dei.uminho.pt

\author{
Luís F.Silva \\ University of Minho \\ Dep.Mech.Engineering \\ Campus de Azurém \\ 4800-058 Guimarães, \\ Portugal \\ 1ffsilva@dem.uminho.pt
}

\begin{abstract}
The industrial manufacturing of sewn products has always been one of the critical processes of the textile chain concerning quality assurance. Assuring the appropriate set-up and operation of all the machines, and thus the final seam quality, is a very complex task. Traditionally, this task is accomplished by empirical methods, with machine setting and quality control relying on the skills of operators and technicians.

In this work, an approach to a more knowledge-based and integrated process planning and control is presented. A system was developed to measure and analyze the most important mechanical effects occurring during high-speed sewing.
\end{abstract}

A general overview over this development is given in this paper.

Key Words: Sewing, sewing parameters, sewing control and monitoring

\section{INTRODUCTION}

The end of the 20th century has brought important new trends in fashion design, marketing tools and consumer attitudes that have reshaped the demands on the textile and apparel industry. The main consequences to apparel manufacturing have been a constant increase of individual production orders, product and materials variety and much smaller order quantities.

This fact posed new requirements on the production systems and equipment: both have to be flexible and reliable. In the case of the equipment, this means that quicker set-up times are required

The authors are grateful to FCT (Fundação para a Ciência e Tecnologia), project funding POSI/SRI/38944/2001 whenever material changes and that quality assurance has to be much more efficient.

Managing this situation with the traditional empirical machine set-up and process planning methods is difficult. Better control and predictability of the processes are required. Additionally, in the new and thriving segment of technical textiles, defects may represent failure of product functions, also demanding new methods that provide a more holistic and knowledge-based management and control of the processes.

\section{FLEXIBLE MANUFACTURING, PROCESS CONTROL AND PLANNING}

To address some of the problems stated previously, in particular the quick response to small production orders, several new production organization methods have been devised. These are based on higher flexibility and interchangeability of the operators, smaller production units and batch sizes, and higher mobility of the production equipment. But the simple reorganization of production cannot address all issues: the variables related to the production process itself are still not controlled. Set-up of the machines is empirical and thus inaccurate and time-consuming. Initial set-up is maintained during operation regardless changing sewing conditions. Quality is assessed by visual inspection, often causing defective parts to pass unnoticed or to be detected very late.

The approach proposed in this work relies on the evaluation and analysis of the relevant sewing parameters and their relation to quality problems and machine set-up variables. This integrated approach has enabled the development of methods to automatically detect sewing defects and seam quality, and to propose control methods for certain machine adjustments. 
The objectives are therefore twofold. On one hand, they are directed to the development of monitoring and control devices for the machines, enabling them to adapt to variable sewing conditions and detect defective sewing conditions automatically. On the other hand, they aim at the establishment of testing methods and equipment for pre-production analysis of fabric "sewability".

\section{THE TEST EQUIPMENT}

The developed measurement system is based on a Singer 882 overedge machine configured to produce the three-thread stitch type 504. Several sensors measuring the relevant process parameters have been applied to the machine. The sensors' signals are conditioned by custom-developed hardware and are then connected to a data acquisition board plugged to the PC. A software package developed in LabView acquires, stores, displays and analyses the signals [[1],[3]].

The test rig measures sewing process variables related to three different sub-functions of the machine: Needle penetration, fabric feeding and thread interlacing or stitch formation.

The pick-up of needle penetration forces is achieved by a commercial piezoelectric sensor (Kistler) that is inserted into the needle-bar as shown in Fig. 1.

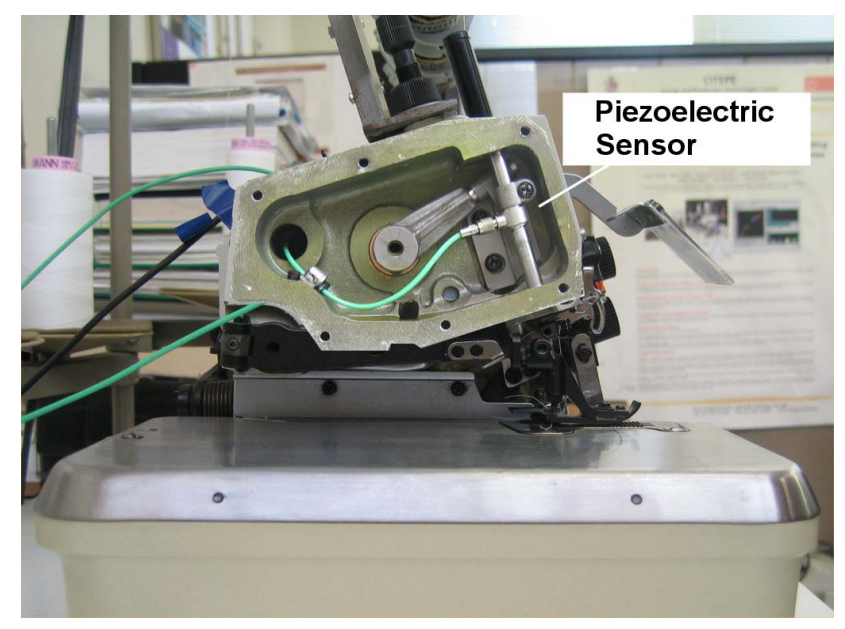

Fig.1: Set-up of the sensor for needle penetration force measurement

To assess the fabric feeding behavior, a piezoelectric sensor was applied to the presser-foot bar as shown in Fig. 2. This sensor measures the dynamic forces on the presser-foot bar and the spring. Additionally, an LVDT has been incorporated to indicate vertical displacement of the presser-foot.[[1],[6]].

${ }^{1}$ Sewability Testing: Evaluation of materials, regarding aspects that can assure or impair seam quality

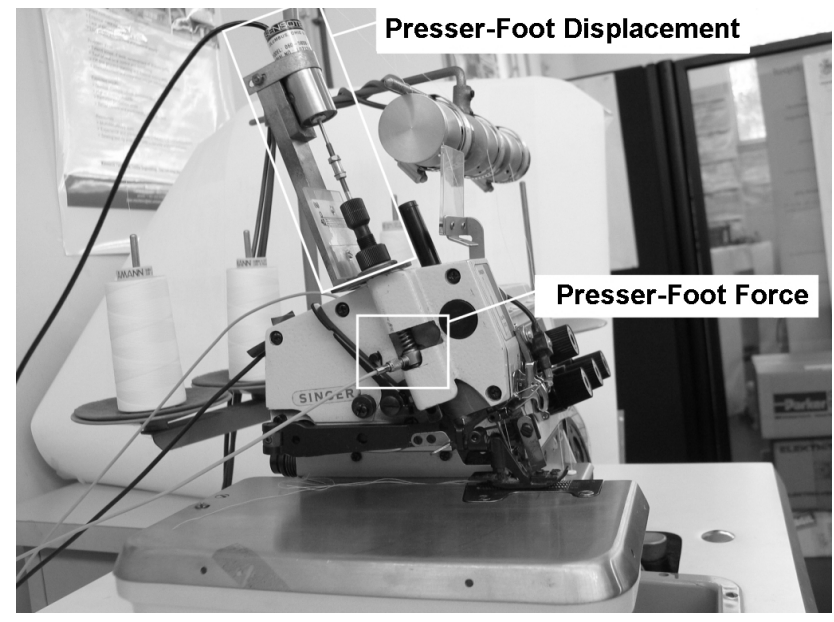

Fig.2: Set-up of the sensors for feeding behavior assessment

Stitch formation is described by the thread pulling forces and thread consumptions. Fig. 3 shows the set-up of the sensors. Thread forces are sensed by semiconductor strain gages applied to the base of a metallic beam. To measure thread consumption, digital encoders have been equipped with wheels where the sewing threads are wound. The pulses produced by the passing thread are then counted during seam formation[[1],[4]].

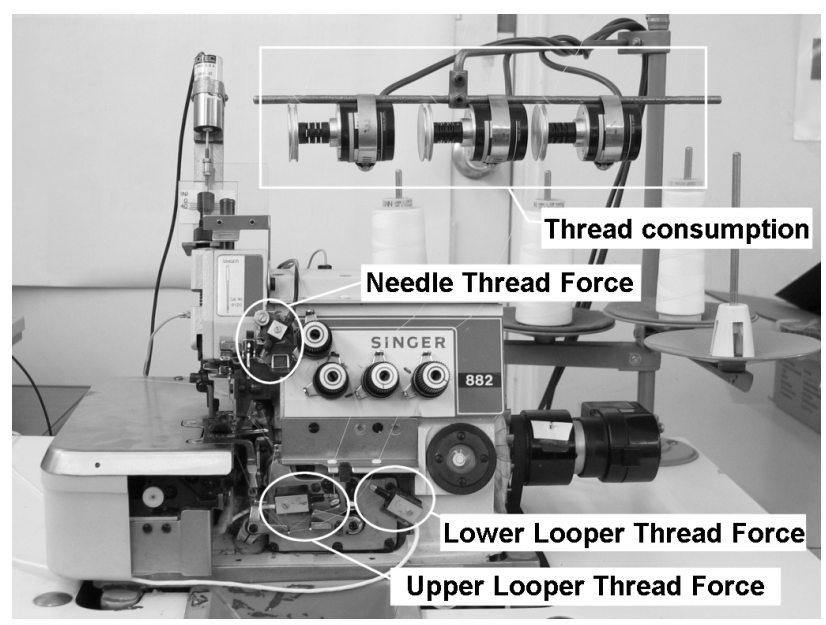

Fig. 3: Sensors measuring parameters related to stitch formation: thread force and thread consumption

The software, developed in the LabView programming environment, is the most important component of the system. It provides extensive functionalities to support the study of the sewing variables. [[1]]

The first of these are the signal acquisition functions that allow the user to quickly perform a seam or a set of seams, display and store them. Included are also very effective graphing functions, 
with multiple zoom and pan capabilities on the graphs, allowing a detailed analysis of the signals.

Finally, and most relevantly, the software provides an extensive set of analysis functions. These include a complete set of functions specifically designed to process each individual sewing parameter, computing, displaying and testing the results against pre-defined limits. Additionally, some general-purpose tools like FFT-processing, digital filtering, peak detection, and other functions are available.

In the current state of development, it is possible to perform a seam and immediately obtain complete results concerning the evaluation of machine operation in its different aspects.

\section{ANALYSIS OF SEWING PARAMETERS}

\section{A. Needle penetration force measurement}

Measuring needle penetration and withdrawal forces is very difficult. Sensing penetration and withdrawal forces with a single sensor is only possible by inserting a sensor into the needle bar. The possible mechanical set-up in the machine used is the one represented in Fig. 1.

In this configuration, the signal picked up by the sensor contains three distinct components:

- Forces necessary for needle bar motion;

- Forces produced by the interaction between needle/thread and fabric

- Forces produced on the needle bar by thread motion;

Of these three components, only the one related to penetration and withdrawal forces is interesting for the measurement. The remaining can be considered parasitic. To extract the relevant component of the signal, a special technique was developed and optimized. This technique, described in [[1],[2]], involves some error, but its accuracy is enough for comparative analysis and approximate indication of actual force values.

Fig. 5 shows a typical needle bar signal after filtering, over one complete penetration.

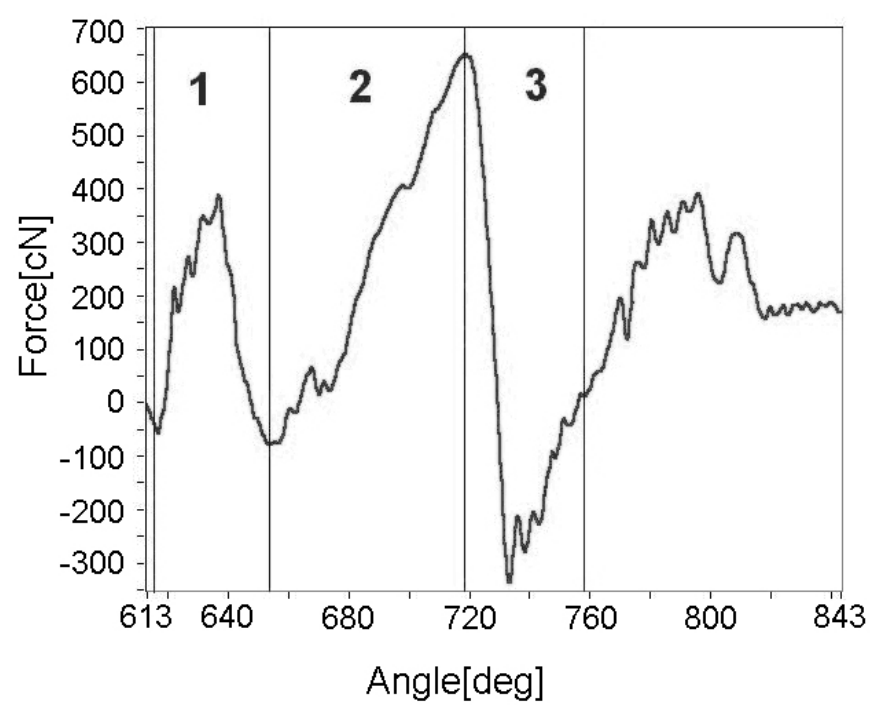

Fig.5: Typical needle penetration force waveform

The shape of the penetration signal varies according to the material, sewing speed, and is also highly variable from one stitch to another. Nevertheless, observing the waveforms and considering the angles at which penetration and withdrawal occurs, it can be concluded that the needle penetration process is divided in the following three phases (also marked in Fig. 5):

- First contact of needle tip with the fabric, a first force peak is produced;

- The needle passes through the fabric. The shaft penetrates and produces a second peak;

- The needle inverts its movement and the fabric holds the needle, producing a third, inverted force peak (a valley).

In each of the three phases described certain features are calculated. The most representative features are the peaks/valley and power. The latter is able to describe the signal for the whole phase interval, whilst the peak measurement delivers a value that is measured on a single sample (where the peak has occurred).

After this processing, the feature values extracted may be represented in two ways:

- A graph in which the values for each feature are plotted according to their chronological order;

- A 3-dimensional graph, in which a point is plotted for each stitch, being its coordinates the 3 feature values extracted from the stitch.

The two representations are complementary, but the latter gives a clearer and wider overview of the needle penetration behavior when comparing different situations. Fig. 6 shows an example, in which a knitted fabric in three different finishing states (raw material, dyed only and finished with softener) has been sewn 
with a Nm70 needle and a Nm120 needle $(0,7 \mathrm{~mm}$ diameter versus $1.2 \mathrm{~mm}$ diameter)

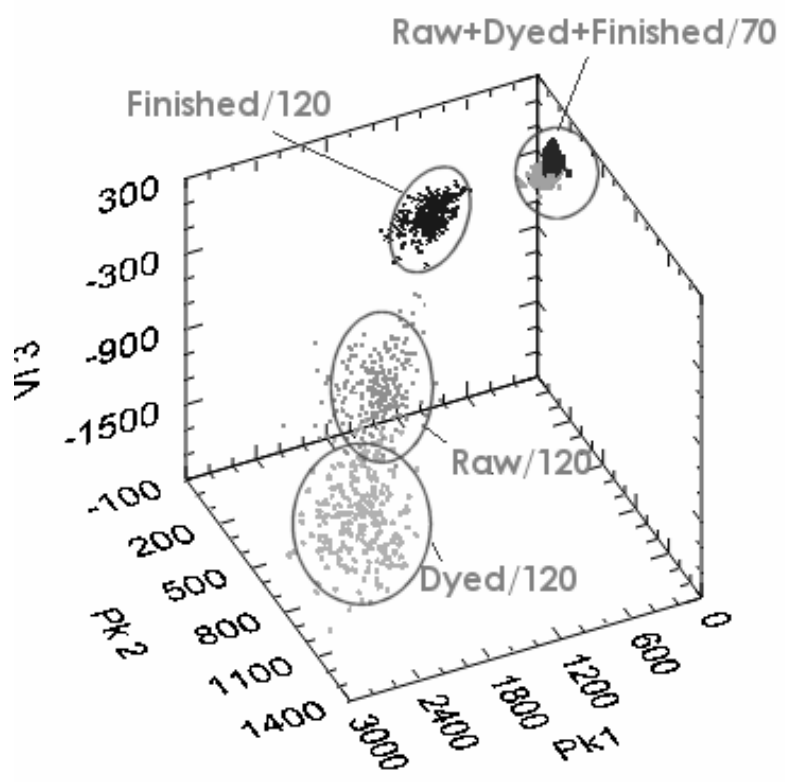

Fig. 6: Peak1/Peak2/Valley 3 of needle penetration force obtained with fabric in three finishing states and two different needle sizes

\section{B. Stitch Formation analysis}

The 504 overlock stitch uses three threads: the needle, lower looper and the upper looper threads. Typical waveforms of needle thread tension are represented in Fig. 7. They were acquired at 3700 stitches per minute (spm) using the same thread tension adjustment on 2 and 4 plies of an interlock knitted fabric.

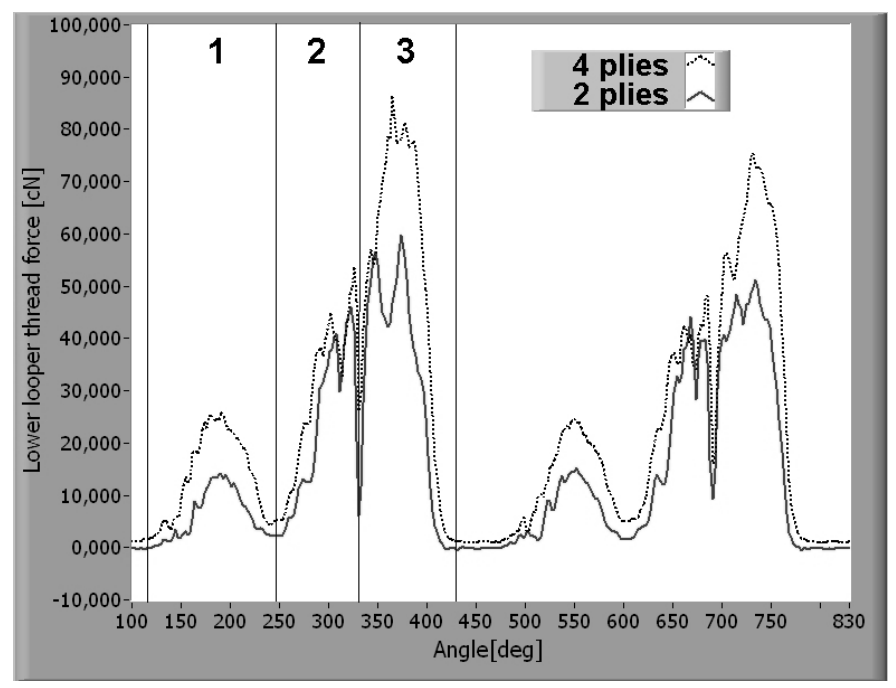

Fig. 7: Needle thread tension over two stitch cycles. Two (solid) and four plies (dashed) of an interlock knitted fabric
Similarly to needle penetration signals, the thread tension waveforms are divided into phases and features are computed in those phases. It has been possible to establish relationships between sewing defects and the values and relation between the features. Skip stitch detection, for instance, is very effectively done using these values.[[1],[4],[5]]

Besides the tools to analyze thread force signals dynamically, the exact quantification of thread pre-tension adjustment is also possible using a specific function provided by the system. This makes it possible to relate the pre-tension adjustment to the dynamic thread forces during sewing.

The measurement of thread consumption has been an important addition to the analysis of stitch formation. Thread consumption is able to indicate if thread tension is correct in both the amount and balance between threads. Given the geometrical parameters of the stitch (fabric thickness, stitch length and width), it is possible to compute an expected value of thread consumption for each thread and compare it to the actual measure to assess the correct adjustment of tensions in both balancing and overall amount. Using the presser-foot displacement sensor, the system provides a function to obtain a measure of fabric thickness to be used in the computation.

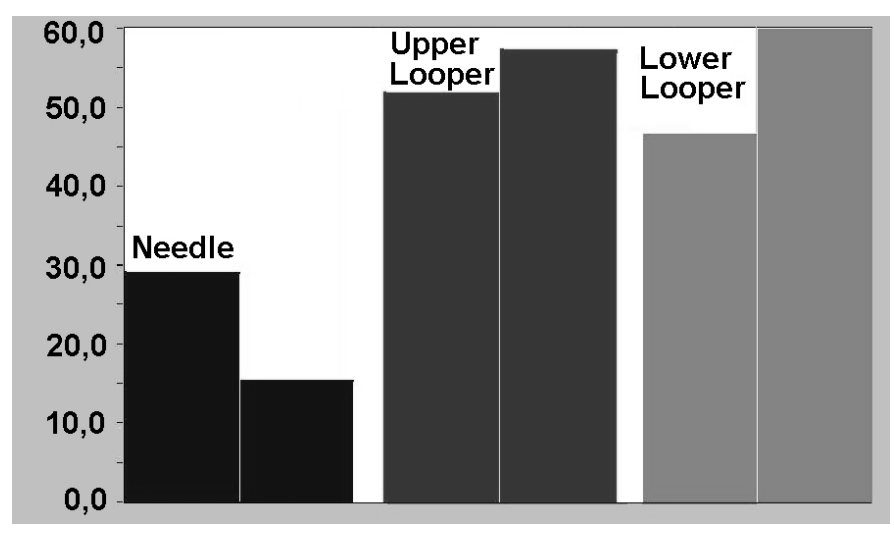

Fig. 8: Thread Consumption balance when increasing needle thread tension (left to right)

Fig. 8 describes a situation in which a balanced stitch has been unbalanced by increasing the pre-tension of the needle thread. As expected the stitch has been tightened at the needle thread and thus needle thread consumption diminished and the consumption in the remaining threads increased.

\section{Analysis of feeding behavior}

To analyze the performance of the feeding system, two variables are measured: Presser-foot displacement and force on the presser-foot bar.[[1],[6],[7]]

Typical waveforms of presser-foot displacement in a low and a high-speed situation are depicted in Fig. 9. The sample spans two stitch cycles. 


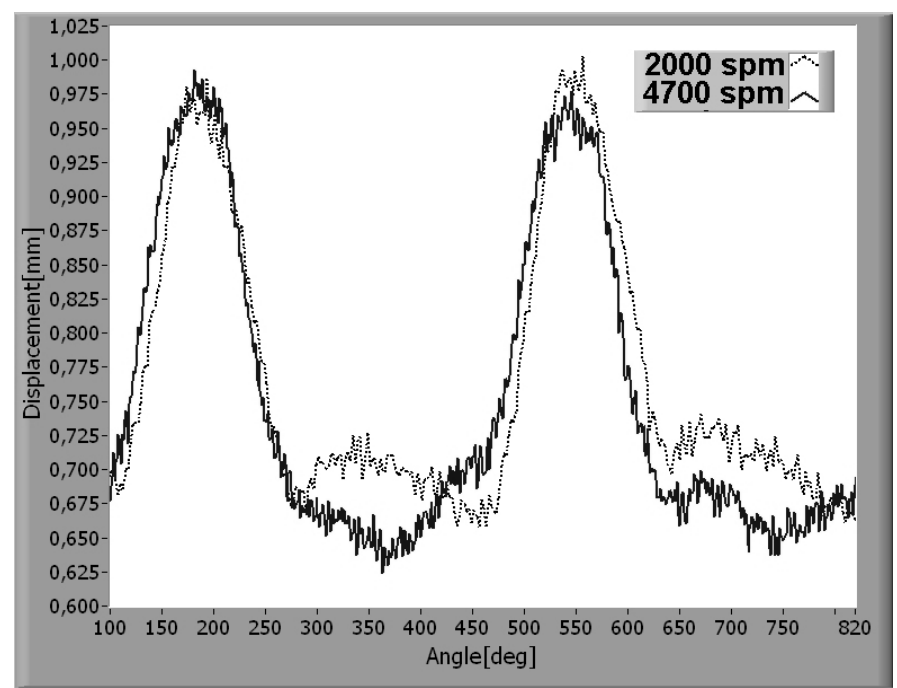

Fig. 9: Presser-foot displacement waveforms at a low-speed (2000 spm, solid) and a high speed-situation (4700 spm, dashed)

As represented in the figure, presser-foot displacement can also be divided in phases:

Phase 1 is the feeding phase, in which the feed-dog emerges from the throat plate and pushes the fabric. The presser-foot should in this phase ideally accompany the vertical component of the feed-dog's movement;

Phase 2 is the needle penetration phase, in which the presserfoot should hold the fabric firmly against the throat plate.

However, Fig. 9 shows that the presser-foot describes different trajectories depending on sewing speed. Especially during phase 2 there is a deviation from the ideal situation: when the feed-dog disappears under the throat plate, the presser-foot bounces and eventually looses contact with the fabric.

Other methods of assessing feeding behavior have been developed, based on presser-foot force and displacement signals.

The studies carried out on the feeding system have led to the development of an active actuator, as well as control methods and references for this actuation [[6],[7]].

\section{CONCLUSIONS}

The tools developed in this work for sewing parameter analysis cover a comprehensive series of aspects of seam production efficiency. For all of the machine's subfunctions, it is possible to obtain quantitative information describing aspects related to seam quality and localized defects. The productivity of the experimental work has been greatly boosted by the easy-to-use functions of the software.
A series of experiments have been devised to examine the relevant sewing variables, considering varying sewing conditions. These experiments have been tailored to allow studies targeted at machine adjustments and the properties of materials, threads and needles. [[1],[4],[6]]

This research is essential to the development of control and monitoring systems to render the machines adaptive and selfmonitored, thus increasing their flexibility and quality of the final product.

\section{REFERENCES}

[1] Carvalho, H. "Optimisation and Control of processes in Apparel Manufacturing." PhD diss., School of Engineering, University of Minho, Portugal, 2004

[2] Carvalho, H., Ferreira, P. Rocha, A., Monteiro,J. “ Signal Feature Extraction for Sewing Analysis using Non-Linear Techniques", (paper presented at IEEE International Symposium on Industrial Electronics, Rio de Janeiro, Brazil, 2003), IEEE, Proceedings in CD-ROM

[3] Carvalho, H., Monteiro,J., Ferreira;F.N. "Measurements and Feature Extraction in High-Speed Sewing", (paper presented at the IEEE International Symposium on Industrial Electronics, Universidade do Minho, Guimarães, 1997. Proceedings of the ISIE'97, Vol.3, 961-966

[4] Carvalho, M. "Estudo das relações entre os parâmetros de controlo, propriedades dos materiais e condições de regulação numa máquina de costura corta-e-cose (Study of the relations between the control parameters and adjustment conditions on an overedge sewing machine)", PhD diss., University of Minho, Portugal, 2003

[5] Carvalho, M., Ferreira, F. N. "Seam Qualification and Control of Parameters in an Overlock Sewing Machine" (paper presented at The Fiber Society Technical Meeting, University of Minho, Portugal, 2000), Proceedings pp. 8992

[6] Silva, L. F. "Estudo de Mecanismos Alternativos de Controlo do Sistema de Alimentação de Máquinas de Costura Industriais (Study of an Alternative Fabric Feeding Control System for Industrial Sewing Machines)", PhD diss., University of Minho, Portugal, 2002.

[7] Silva, L. F., Lima, M., Carvalho, H., Rocha, A. M., Ferreira, F. N., Monteiro, J. L., Couto, C., "Actuation, Monitoring and Closed-loop Control of Sewing Machine Presser Foot", Transactions of the Institute of Measurement and Control, Vol. 25, N.5, Arnold Journals, United Kingdom, 2003.

[8] Chmielowiec, R., Lloyd, D. W., , "The Measurement of Dynamic Effects in Commercial Sewing Machines", Proceedings of The 3rd Asian Textile Conference, Vol. II, pp. 814-828, 1995 
[9] Greenberg, N. G., “An instrument for measurement of thread dynamic tension characteristics during the sewing operation - Part 2", Clothing Research Journal, 3, No 2, pp. 77, 1975

[10] Clapp, T. G., Little, T. J., Thiel, T. M., Vass, D. J., "Sewing Dynamics: Objective Measurement of Fabric/Machine Interaction", International Journal of Clothing Science and Technology, Vol. 4, №. 2/3, pp. 45-53, 1992.

[11] Matthews, B. N., Little, T. J., "Sewing Dynamics, Part I: Measuring Sewing Machine Forces at High Speeds", Textile Research Journal, 58, July, 1988, pp. 383-391.

[12] Stylios, G., Sotomi, J. O., "Thinking Sewing Machines for Intelligent Garment Manufacture", International Journal of Clothing Science and Technology, Vol. 8, No. 1/2, pp. 4455,1996 